\title{
Anticandidal activity of biosynthesized silver nanoparticles: effect on growth, cell morphology, and key virulence attributes of Candida species
}

This article was published in the following Dove Press journal: International Journal of Nanomedicine

Mohammad Jalal ${ }^{1, *}$

Mohammad Azam Ansari ${ }^{2, *}$

Mohammad A Alzohairy ${ }^{3}$

Syed Ghazanfar Ali'

Haris M Khan'

Ahmad Almatroudi ${ }^{3}$

Mohammad Imran Siddiqui ${ }^{4}$

'Department of Microbiology, Jawaharlal Nehru Medical College and Hospital,

Aligarh Muslim University, Aligarh

202002, India; ${ }^{2}$ Department of Epidemic

Disease Research, Institutes for Research and Medical Consultations (IRMC), Imam

Abdulrahman Bin Faisal University,

Dammam 3|44I, Saudi Arabia;

${ }^{3}$ Department of Medical Laboratories,

College of Applied Medical Sciences,

Qassim University, Qassim 5143I, Saudi

Arabia; ${ }^{4}$ Department of Environmental

Engineering, Zakir Husain College of

Engineering and Technology, Aligarh

Muslim University, Aligarh 202202, India

*These authors contributed equally to this work
Correspondence: Mohammad Azam Ansari Department of Epidemic Disease Research, Institutes for Research and Medical Consultations (IRMC), Imam Abdulrahman Bin Faisal University, Dammam 3I44I, Saudi Arabia

Email maansari@iau.edu.sa

Mohammad Jalal

Department of Microbiology, Jawaharlal

Nehru Medical College and Hospital, Aligarh

Muslim University, Aligarh 202002, India

Email jalalmicrol98I@gmail.com
Purpose: The pathogenicity in Candida spp was attributed by several virulence factors such as production of tissue damaging extracellular enzymes, germ tube formation, hyphal morphogenesis and establishment of drug resistant biofilm. The objective of present study was to investigate the effects of silver nanoparticles (AgNPs) on growth, cell morphology and key virulence attributes of Candida species.

Methods: AgNPs were synthesized by the using seed extract of Syzygium cumini (Sc), and were characterized by UV-Vis spectrophotometer, Fourier-transform infrared spectroscopy (FTIR), scanning electron microscopy (SEM), energy-dispersive X-ray (EDX), and transmission electron microscopy (TEM). ScAgNPs were used to evaluate their antifungal and antibacterial activity as well as their potent inhibitory effects on germ tube and biofilm formation and extracellular enzymes viz. phospholipases, proteinases, lipases and hemolysin secreted by Candida spp.

Results: The MICs values of ScAgNPs were ranged from $0.125-0.250 \mathrm{mg} / \mathrm{ml}$, whereas the MBCs and MFCs were 0.250 and $0.500 \mathrm{mg} / \mathrm{ml}$, respectively. ScAgNPs significantly inhibit the production of phospholipases by $82.2,75.7,78.7,62.5$, and $65.8 \%$; proteinases by 82.0 , $72.0,77.5,67.0$, and $83.7 \%$; lipase by $69.4,58.8,60.0,42.9$, and $65.0 \%$; and hemolysin by 62.8, 69.7, 67.2, 73.1, and 70.2\% in C. albicans, C. tropicalis, C. dubliniensis, C. parapsilosis and C. krusei, respectively, at $500 \mu \mathrm{g} / \mathrm{ml}$. ScAgNPs inhibit germ tube formation in C. albicans up to $97.1 \%$ at $0.25 \mathrm{mg} / \mathrm{ml}$. LIVE/DEAD staining results showed that ScAgNPs almost completely inhibit biofilm formation in C. albicans. TEM analysis shows that ScAgNPs not only anchored onto the cell surface but also penetrated and accumulated in the cytoplasm that causes severe damage to the cell wall and cytoplasmic membrane.

Conclusion: To summarize, the biosynthesized ScAgNPs strongly suppressed the multiplication, germ tube and biofilm formation and most importantly secretion of hydrolytic enzymes (viz. phospholipases, proteinases, lipases and hemolysin) by Candia spp. The present research work open several avenues of further study, such as to explore the molecular mechanism of inhibition of germ tubes and biofilm formation and suppression of production of various hydrolytic enzymes by Candida spp.

Keywords: ScAgNPs, virulence factors, hydrolytic enzymes, germ tubes, biofilm, LIVE/ DEAD staining.

\section{Introduction}

Candida spp. is one of the most common opportunistic human fungal pathogens, which are responsible for $90-100 \%$ of mucosal infections and the fourth-leading cause of nosocomial infections (candidemia and other forms of invasive candidiasis) that attribute a $35-50 \%$ mortality rate in immunocompromised and critically ill 
individuals. ${ }^{1,2}$ Approximately $70 \%$ of women experienced vaginal infections by Candida spp, $70 \%$ of AIDS patients had oropharyngeal candidiasis, and $20 \%$ of them suffered from recurrence. ${ }^{3}$ Extracellular hydrolytic enzymes, most importantly proteinases, phospholipases, hemolysin, and lipases, are believed to play an important role in Candida overgrowth because these facilitate adherence, tissue penetration, and the subsequent invasion to the host. ${ }^{4}$ The formation of biofilms, communities of adhered cells that are embedded and encased in an extracellular polymeric matrix on both kind of surfaces, either abiotic or biotic (such as implanted medical devices and tissues), also play a major role in pathogenicity. ${ }^{5}$ It is believed that cells in a biofilm exhibit high resistance to antifungal drug and the host immune system, primarily due to inadequate penetration of antifungal agents. ${ }^{6}$ Due to the production of various extracellular hydrolytic tissue-damaging enzymes, hyphae transition, and formation of highly drug-resistant biofilm in isolates of Candida spp, innovative strategies are needed to develop newer and safer antifungal agents with broad-spectrum activity that suppress and eradicate the virulence factors involved in the pathogenicity of life threatening Candida spp. In most cases candidiasis is treated with the existing conventional antifungal drug that includes triazoles and polyene. Over the past decade the improper and misuse of existing antifungal drugs have led to the development of drugresistant clinical isolates of Candida spp. Recently, nanomedicines have gained great attention to formulate nanoparticles based on antimicrobial agents which have the potential to combat microbial drug resistance either alone or in combination with existing drugs. The antimicrobial activity of biogenic AgNPs was well documented in the literature. ${ }^{7-21}$ However, there are very few studies available in the literature on the inhibition of production of various extracellular hydrolytic enzymes and germ tubes in Candida spp by nanoparticles. $^{22-24}$ Due to the scarcity in the literature on the inhibition of production of various virulence factors by Candida spp, herein for the first time we have reported the potent inhibitory effects of green synthesized AgNPs on the production of different virulence attributes of Candida species isolated from oropharyngeal mucosa of HIV patients. The objective of the present study was i) the green synthesis of silver nanoparticles (AgNPs) using aqueous seed extract of Syzygium cumini (Sc). ii) Characterization of as-prepared ScAgNPs by a UV-Vis spectrophotometer, fourier-transform infrared spectroscopy (FTIR), scanning electron microscopy (SEM), energy-dispersive X-ray (EDX), and transmission electron microscopy (TEM). iii) Evaluation of antifungal and antibacterial activity of ScAgNPs against $C$. albicans, C. tropicalis, C. parapsilosis, C. neoformans, S. aureus, and E. coli using microbroth dilution, well diffusion, and timedependent growth assay methods. iv) Investigation of potent inhibitory effects of green synthesized ScAgNPs on key virulence factors such as germ tube formation and extracellular enzymes viz. phospholipases, proteinases, lipases, and hemolysin secreted by Candida spp. v) Visualization of effects of ScAgNPs on biofilm formation by Congo red agar and Confocal laser scanning microscopy (CLSM), and vi) Examination of ultrastructural alteration caused by ScAgNPs in C. albicans by TEM.

\section{Materials and methods}

\section{Preparation of the seed extract and biosynthesis of ScAgNPs}

The fresh seeds of Syzygium cumini were washed with sterile water, and air-dried. About $10 \mathrm{~g}$ of seeds were ground to fine powder and dissolved in $100 \mathrm{~mL}$ sterile water, vigorously vortexed, and then boiled for 20 minutes. After cooling, the solutions were filtered by Whatman No. 1 paper (Maidstone, UK) and then the filtrate was collected and stored at $4{ }^{\circ} \mathrm{C} .^{25}$ For the synthesis of AgNPs, $25 \mathrm{~mL}$ of aqueous seed extract was transferred into $75 \mathrm{~mL}$ of $1 \mathrm{mM}$ silver nitrate $\left(\mathrm{AgNO}_{3}\right.$, Sigma Aldrich, St. Louis, MO, USA) solution. The mixture was kept at room temperature overnight. The change in color of the solution from pale yellow to dark brown was an indication of the formation of AgNPs. The solution was washed with double distilled water three times at 14,000 rpm for 10 minutes to separate the AgNPs. ${ }^{25}$

\section{Characterization of ScAgNPs}

The biosynthesized SCAgNPs were characterized by UV-Vis spectroscopy (LAMBDA 25, Perkin Elmer, USA), FT-IR spectrometer (SHIMADZU-8400, Japan), energy dispersive X-ray spectroscopy (JED-2300, Japan), scanning electron microscopy (SEM, JSM-6510LV, Jeol Ltd., Tokyo, Japan) and transmission electron microscopy (TEM, 2100, Jeol) by following the protocol of our previous study. ${ }^{26}$

\section{Strains}

The clinical isolates of Candida (C. albicans, C. tropicalis, C. dubliniensis, C. parapsilosis, and C. krusei) and bacterial ( $S$. aureus and $E$. coli) strains used in this study were collected from the department of Microbiology, Jawaharlal Nehru Medical College and Hospital, Aligarh Muslim University, Aligarh, India. 


\section{Antimicrobial activity of ScAgNPs}

The zone of inhibition (in $\mathrm{mm}$ ) test for Candida spp and bacterial stains were carried out on Sabouraud Dextrose Agar (SDA, Hi-Media, Mumbai, India) and Mueller Hinton Agar (MHA, Hi-Media) plates, respectively, by well diffusion methods, as described in a previous study. ${ }^{26}$ The MICs, MBCs, and MFCs values of ScAgNPs against tested strains were examined by microbroth dilution method, as previously described with slight modification. ${ }^{26}$ Further, the effects of ScAgNPs on the growth curve of Candida spp at different time interval and different concentration were determine as described in our previous study. ${ }^{26}$

\section{Effect of ScAgNPs on virulence factors of Candida spp}

Phospolipase activity of untreated and ScAgNPs treated Candida isolates (C. albicans, C. tropicalis, C. dubliniensis, C. parapsilosis, and C. krusei) was assessed as described previously. ${ }^{24,27}$ The anti-proteinase activity of different concentration of green synthesized ScAgNPs against proteinase positive Candida spp were carried out by following the protocol of our previous study. ${ }^{24}$ Lipase activity of control and ScAgNPs treated experiments was carried out using the previously reported protocols. ${ }^{28,29}$ The lysis efficacy of human red blood cells by $C$. albicans after treatment with varying concentration of ScAgNPs was analyzed as previously described methods with some modification. ${ }^{7,30}$ Further, the effect of ScAgNPs on the germ tube formation by $C$. albicans was examined as a method previously reported with some modification. $^{24}$

\section{Effect of ScAgNPs on C. albicans biofilm}

The effects of different concentration of ScAgNPs on $C$. albicans biofilm were assessed by Congo Red Agar method (qualitatively), as described in our previous study with slight modification. ${ }^{31}$ Furthermore, the inhibitory effect of ScAgNPs on biofilm formation of $C$. albicans was quantitatively analyzed and visualized by CLSM (FV1000, Olympus Latin America, Miami, FL, USA) using LIVE/DEAD staining, ie, Con-A-FITC (Sigma Aldrich) and propidium iodide (Sigma Aldrich). ${ }^{24}$

\section{Effects of ScAgNPs on C. albicans morphology and ultrastructure: TEM analysis}

The morphological and ultrastructural alteration in C. albicans cells after treatment with ScAgNPs were examined by TEM ( 2100, Jeol). The sample preparation and analysis methods were similar to those described previously. ${ }^{24}$

\section{Results and discussion}

\section{Structural characterization of biosynthesized ScAgNPs}

In the present study, aqueous seed extract of Sygyzium cumini, a traditional medicinal plant, has been used as a reducing and stabilizing agent for the green synthesis of AgNPs. The bioreduction of $\mathrm{Ag}^{+}$ions to $\mathrm{Ag}^{0}$ by seed extract of Sygyzium cumini and formation of AgNPs was confirmed by UV-Vis absorbance spectroscopy, which showed an intense peak at $474.45 \mathrm{~nm}$ due to surface plasmon resonance (Figure 1) and is supported by the results of Banerjee and

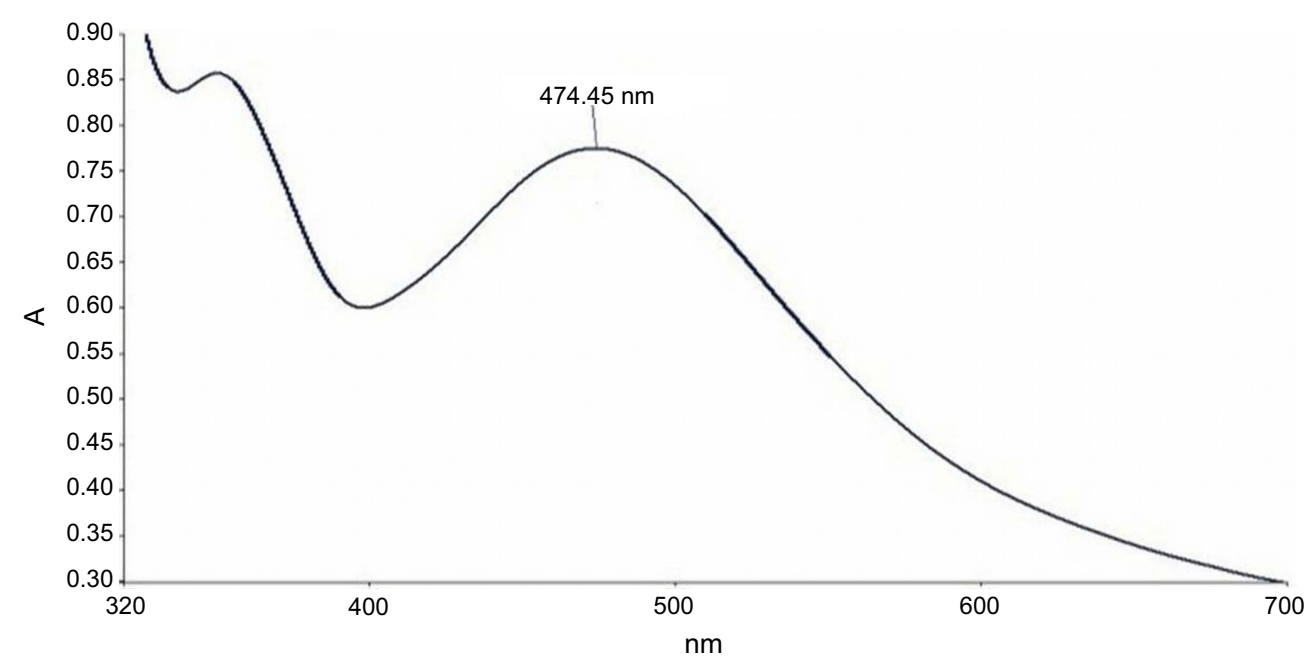

Figure I UV-Vis spectrum of AgNPs synthesized by aqueous seed extract of Sygyzium cumini.

Abbreviation: AgNPs, silver nanoparticles. 


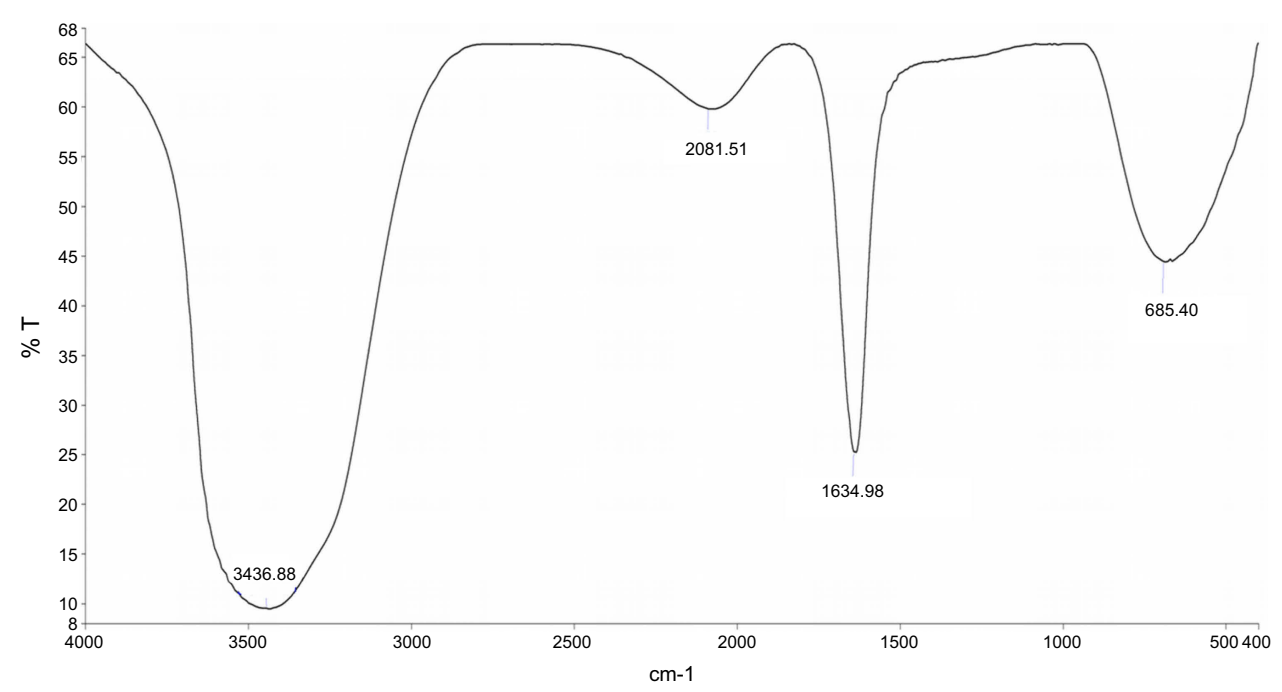

Figure 2 FTIR Spectrum of AgNPs synthesized by aqueous seed extract of Sygyzium cumini. Abbreviations: AgNPs, silver nanoparticles; FTIR, Fourier-transform infrared spectroscopy.

Narendhirakannan. ${ }^{32}$ The FTIR spectra (Figure 2) showed a broad peak at $3,436.88 \mathrm{~cm}^{-1}$, indicating the presence of hydroxyl group of polyphenolic component in seed extract. ${ }^{32}$ It has been reported that the seed extract of $S$. cumini contains a large amount of polyphenols, flavonoids, and gallic acid. ${ }^{33}$ The peak at $1,634.98 \mathrm{~cm}^{-1}$ was due to the presence of carbonyl groups $(\mathrm{C}=\mathrm{O})$ of the polyphenolic compounds such as epicatechin gallate, epigallocatechin gallate, catechin gallate, epi-gallocatechin, gallocatechin gallate, theaflavin present in the seed extract. ${ }^{32-34}$ The presence of a large amount of polyphenolic compounds in the seed extract of S. cumini might be responsible for the reduction of $\mathrm{Ag}^{+}$to $\mathrm{Ag}^{0}$ and stabilization of AgNPs. ${ }^{33,34}$ The SEM micrograph revealed that the particles were hexagonal (Figure 3A). EDX analysis

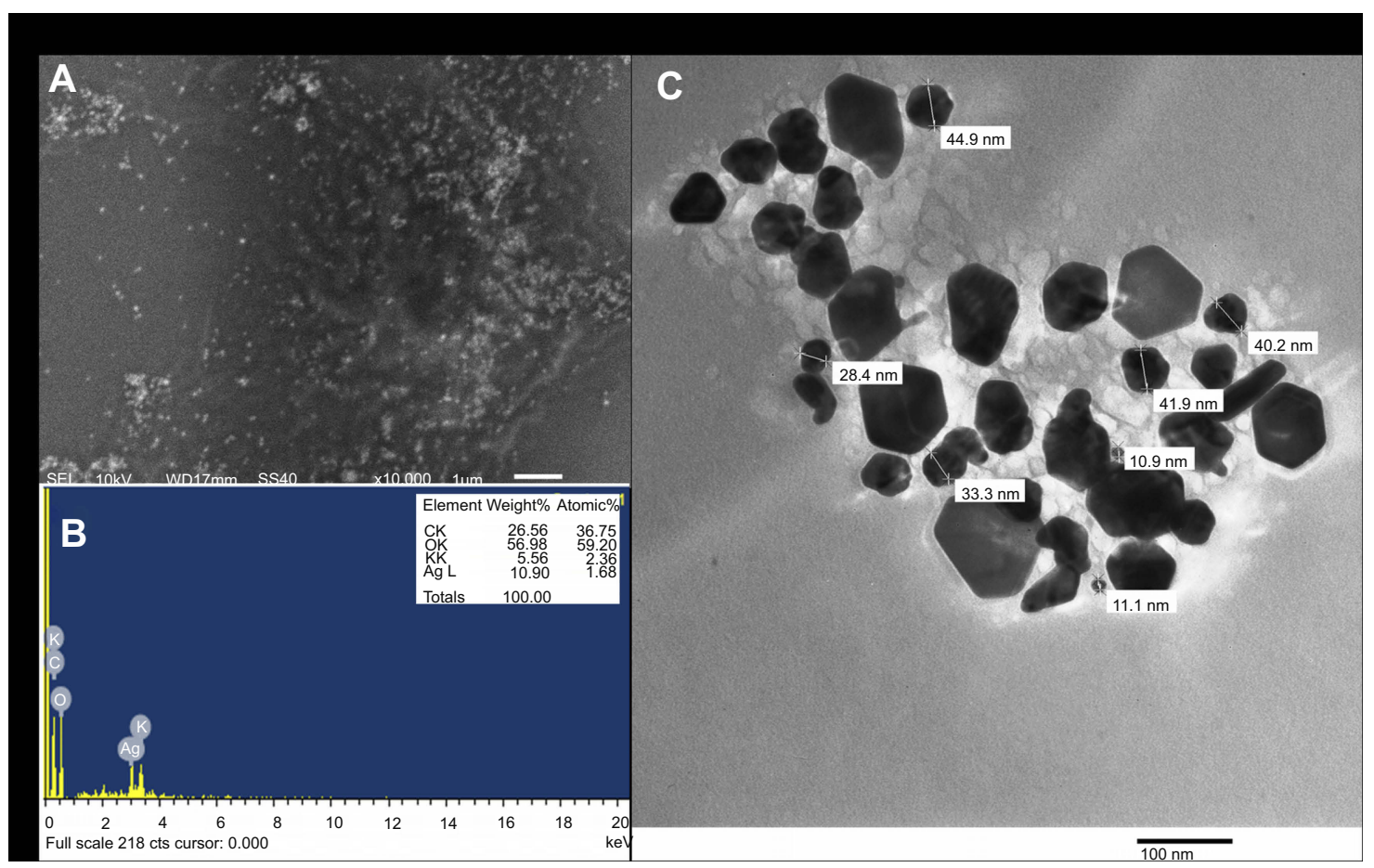

Figure 3 SEM (A) EDX (B); and TEM (C) analysis of AgNPs synthesized by aqueous seed extract of Sygyzium cumini.

Abbreviations: AgNPs, silver nanoparticles; EDX, energy-dispersive X-ray; SEM, scanning electron microscopy; TEM, transmission electron microscopy. 
of the synthesized ScAgNPs showed a typical optical absorption peak at $3 \mathrm{keV}$ that confirmed the presence of elemental silver in the form of $\mathrm{AgNPs}^{33}$ (Figure 3B). The TEM analysis confirms that the shape of ScAgNPs was primarily hexagonal and was in the range of 10-100 nm (Figure 3C).

\section{Antimicrobial activity of ScAgNPs}

The antimicrobial activity of ScAgNPs was assessed by measuring the clear zone of inhibition around the wells supplemented with $0.031-0.5 \mathrm{mg} / \mathrm{mL}$ concentration of ScAgNPs. A significant reduction in the growth of Candida and bacterial species was observed at $0.5 \mathrm{mg} / \mathrm{mL}$ of ScAgNPs (Figure 4). The highest zone of inhibition (22 $\mathrm{mm}$ ) was recorded for $C$. albicans, followed by $C$. neoformans $(21 \mathrm{~mm}), S$. aureus $(20 \mathrm{~mm}), C$. parapsilosis (19 mm), E. coli $(18 \mathrm{~mm})$, and C. tropicalis $(17 \mathrm{~mm})$. The zone of inhibition values obtained here is similar to those reported by Yasir et al. ${ }^{10}$ The MICs values of ScAgNPs against all tested Candida and bacteria species ranged from
$0.125-0.250 \mathrm{mg} / \mathrm{mL}$, whereas the MBCs and MFCs were 0.250 and $0.500 \mathrm{mg} / \mathrm{mL}$, respectively. In a recent study, ${ }^{17}$ AgNPs synthesized by Caesalpinia ferrea seed extract showed MIC values in the range of $156.25-1,250 \mu \mathrm{g} / \mathrm{mL}$, and MFC values in the range of $312.5-5,000 \mu \mathrm{g} / \mathrm{mL}$ against C. albicans, C. glabrata, C. kruzei, and C. guilliermondii. ${ }^{17}$ The MIC and MFC results of the present study demonstrate that the ScAgNPs exhibited high anticandidal activity. Further, the effects of a different concentration of ScAgNPs (ie, $62.5-1000 \mu \mathrm{g} / \mathrm{mL}$ ) on the growth of $C$. albicans, C. tropicalis, and C. parapsilosis examined by time-dependent growth inhibition assay shows that ScAgNPs inhibit the growth of tested candida species at all doses (Figure 5). The growth of Candida species reached exponential phase rapidly in the absence of ScAgNPs. However, it was found that the growth of the Candida cells were significantly reduced when exposed at a higher concentration of ScAgNPs (500 and $1000 \mu \mathrm{g} / \mathrm{mL}$ ). Figure 5 clearly shows that, as the concentration of ScAgNPs

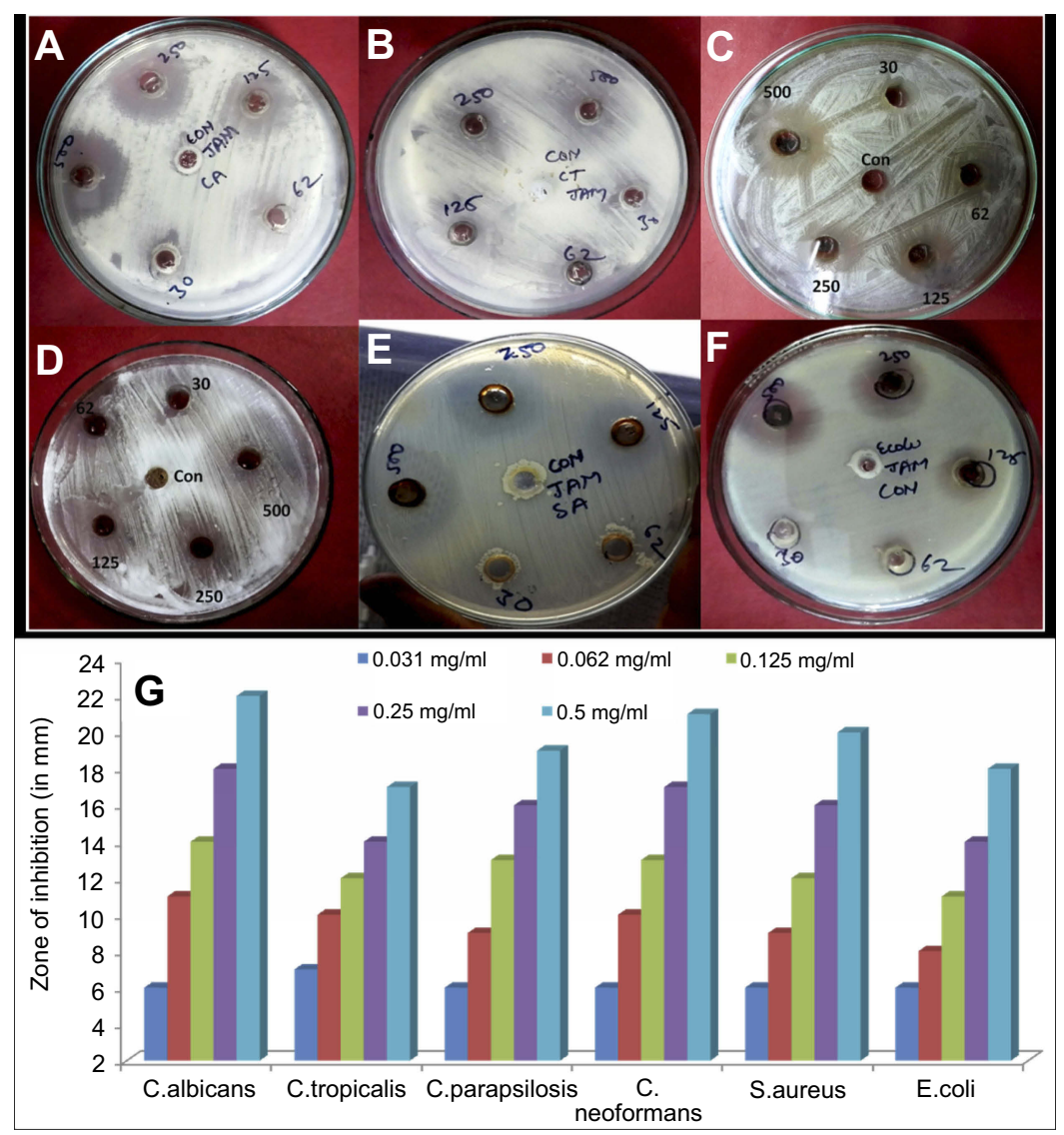

Figure 4 Antimicrobial activity of AgNPs synthesized by aqueous seed extract of Sygyzium cumini against (A) C. albicans; (B) C. tropicalis; (C); C. parapsilosis, (D) C. neoformans; (E) S. aureus, and (F) E. coli. Panel (G) shows zone of inhibition in millimetres.

Abbreviation: AgNPs, silver nanoparticles. 


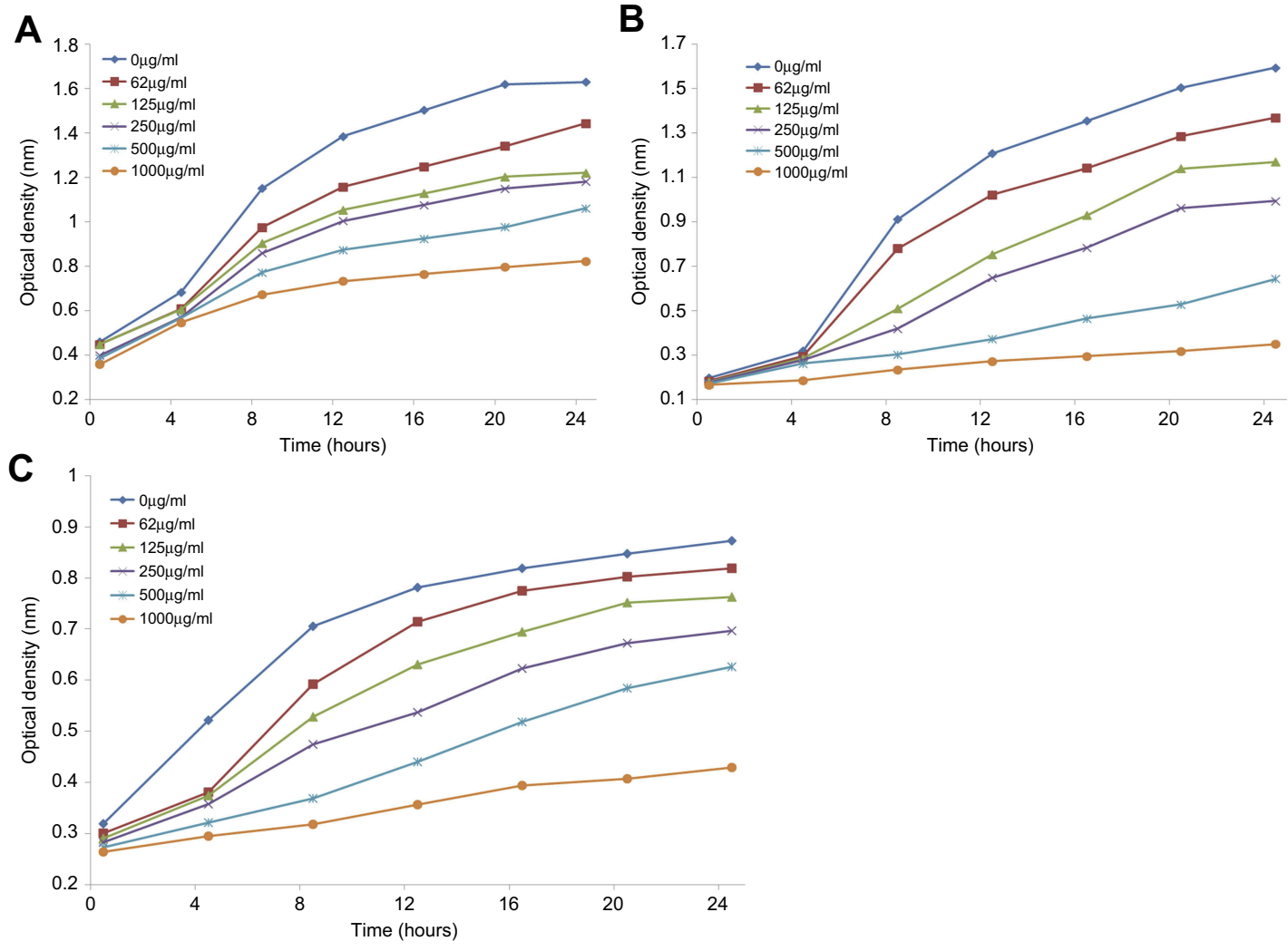

Figure 5 Growth curves of C. albicans (A); C. tropicalis (B); and C. parapsilosis (C) treated with different concentration of ScAgNPs.

increases, the growth inhibition of Candida cells was also increased. Dose-dependent anticandidal activity of AgNPs has been previously reported. ${ }^{26,35}$

\section{Effects of ScAgNPs on extracellular hydrolytic enzymes of Candida spp}

The virulence in Candida species is attributed by a number of extracellular enzymes such as proteinase, phospholipase, lipase, hemolysin, chondroitinase, and hyaluronidase, which plays an important role in its pathogenicity. ${ }^{4,36}$ Thus, interference in these virulence factors has emerged as a novel target for developing new anti-infective agents. However, a huge number of studies on anticandidal activity of AgNPs synthesized by different approaches were reported in the literature..$^{10,15,37-39}$ The effects and mechanism of AgNPs on the production of extracellular enzymes by Candida spp are still not reported. Very little is known about the inhibition of production of virulence factors by nanoparticles. ${ }^{22-24}$ In the present study, for the first time, the inhibitory effects of green synthesized ScAgNPs on the production of phospholipases, SAPs, lipases, and hemolysin by five Candida spp, ie, C. albicans, C. tropicalis, C. dubliniensis, C. parapsilosis, and C. krusei were investigated. Phospholipases are associated to adherence, induction of germ tubes, transition from yeast to hyphal forms, penetration, and tissue injury. ${ }^{4}$ In the present study, it was found that ScAgNPs at $500 \mu \mathrm{g} / \mathrm{mL}$ significantly inhibits production of phospholipases activity by $82.2,75.7,78.7,62.5$, and $65.8 \%$ in $C$. albicans, $C$. tropicalis, $C$. dubliniensis, $C$. parapsilosis, and $C$. krusei, respectively, in a dose-dependent manner (Figure 6). Similar results were previously reported by Jalal et $\mathrm{al},{ }^{24}$ who found that $\mathrm{ZnO}$ NPs synthesized by leaf extract of Crinum Latifolium inhibit the secretion of phospholipases in albicans and non-albicans isolates of Candida. It was observed that the suppression of phospholipases activity in albicans is more pronounced than that of non-albicans isolates (Figure 6).

The production of SAPs by Candida spp has been identified as one of most important virulence factors as it has the ability to degrade a number of human proteins on the lesion site, hemoglobin, albumin, secretory immunoglobulin A, and skin proteins. The proteolytic action of this enzyme also attributed the tissue invasion and penetration. ${ }^{40}$ In the present study, it was found that ScAgNPs at $500 \mu \mathrm{g} / \mathrm{mLinhibits}$ production of SAPs by $82.0,72.0,77.5,67.0$, and $83.7 \%$ in C. albicans, C. tropicalis, C. dubliniensis, C. parapsilosis, and C. krusei, respectively (Figure 7). Similar results were previously reported by Hamid et al, ${ }^{23}$ who found that AgNPs synthesized by fungi Aspergillus spp inhibit the secretion of 


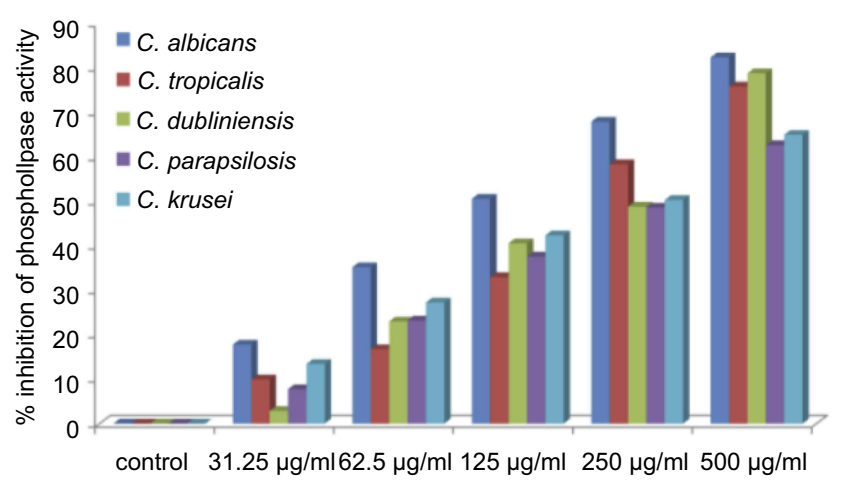

Figure 6 Effects of different concentration of ScAgNPs on production of extracellular phospholipases.

Abbreviation: ScAgNPs, Syzygium cumini silver nanoparticles.

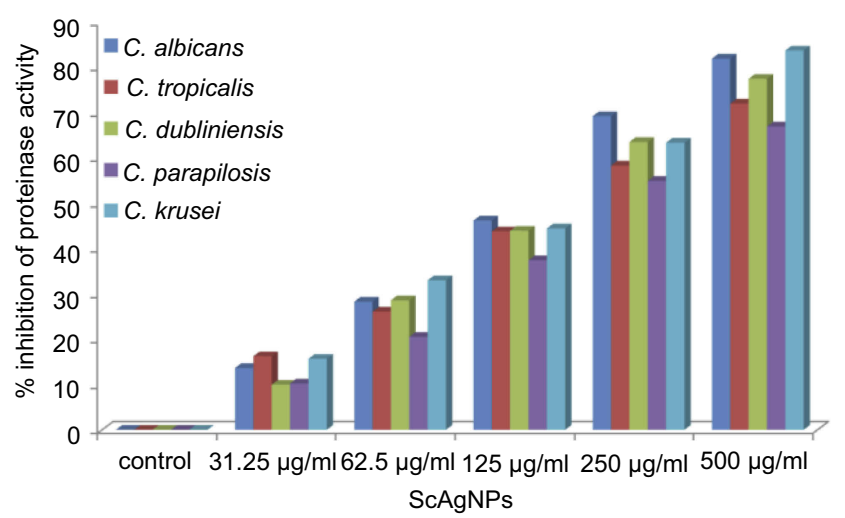

Figure 7 Effects of different concentration of ScAgNPs on production of extracellular secreted aspartyl proteinases.

Abbreviation: ScAgNPs, Syzygium cumini silver nanoparticles.

SAPs in albicans and non-albicans isolates of Candida. In another study, Hajjar et $\mathrm{al}^{22}$ reported the inhibition of $C$. albicans secreted aspartyl proteinase by exploring triangular gold nanoparticles.

Stehr et $\mathrm{al}^{41}$ reported that the secretion of extracellular lipases increases the pathogenicity of Candida by degrading lipids, and may also support the microorganism to stick to host tissue and/or neighboring cells. ${ }^{41}$ In the present study, it was found that ScAgNPs at $500 \mu \mathrm{g} / \mathrm{mL}$ suppress the production of lipases by $69.4,58.8,60.0,42.9$, and $65.0 \%$ in C. albicans, C. tropicalis, C. dubliniensis, C. parapsilosis and C. krusei, respectively (Figure 8). Another putative virulence factors responsible for Candida pathogenesis in humans is secretion of hemolysins by Candida spp. Yeast cells destroy erythrocytes to acquire iron from the host by secreting hemolysins ${ }^{42}$ and the secretion of hemolysins followed by iron obtained facilitates invasion of hyphae and the development of disseminated candidiasis. ${ }^{43}$ In the present study, we found that ScAgNPs at $500 \mu \mathrm{g} / \mathrm{mL}$

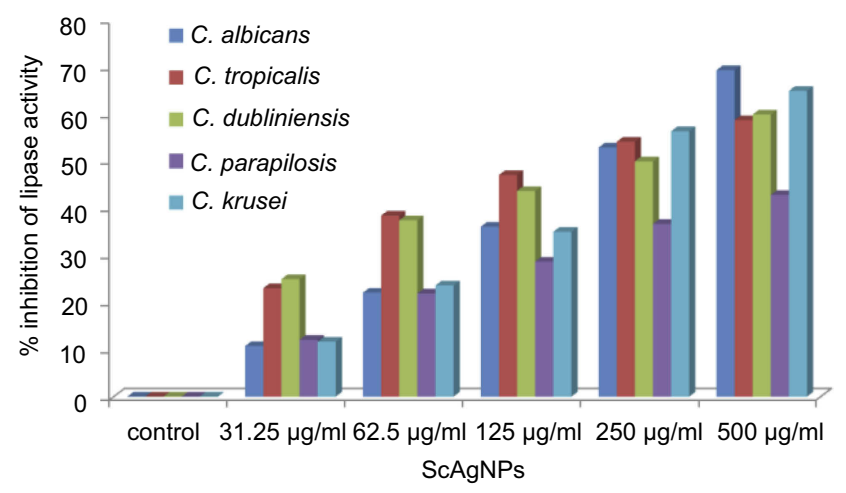

Figure 8 Effects of different concentration of ScAgNPs on lipase activity. Abbreviation: ScAgNPs, Syzygium cumini silver nanoparticles.

suppress the production of hemolysins by $62.8,69.7,67.2$, 73.1 , and $70.2 \%$ in C. albicans, C. tropicalis, C. dubliniensis, C. parapsilosis, and C. krusei, respectively (Figure 9).

\section{Effect of ScAgNPs on germ tube formation}

The morphological transitions between yeast and filamentous forms are probably to be one of the most important virulent factors in C. albicans. ${ }^{44}$ The developments of hyphae or germ tube is an intriguing characteristic of $C$. albicans that plays a crucial role in adherence and biofilm formation, which indeed is essential for colonization and initiation for pathogenesis. ${ }^{45,46}$ Impeding or blocking of transformation from yeast to hyphal form would mean stopping the infection. In this study, it was found that ScAgNPs almost completely impede the germ tube formation in a dose-dependent manner (Figure 10). ScAgNPs inhibits germ tube formation by 97.1, 94.3, 57.1, and

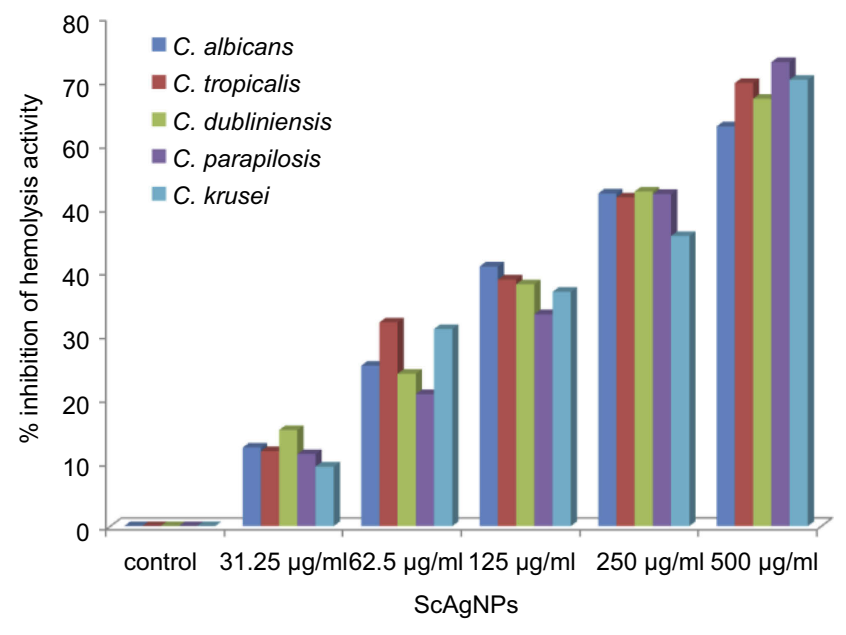

Figure 9 Effects of different concentration of ScAgNPs on hemolysin activity. 


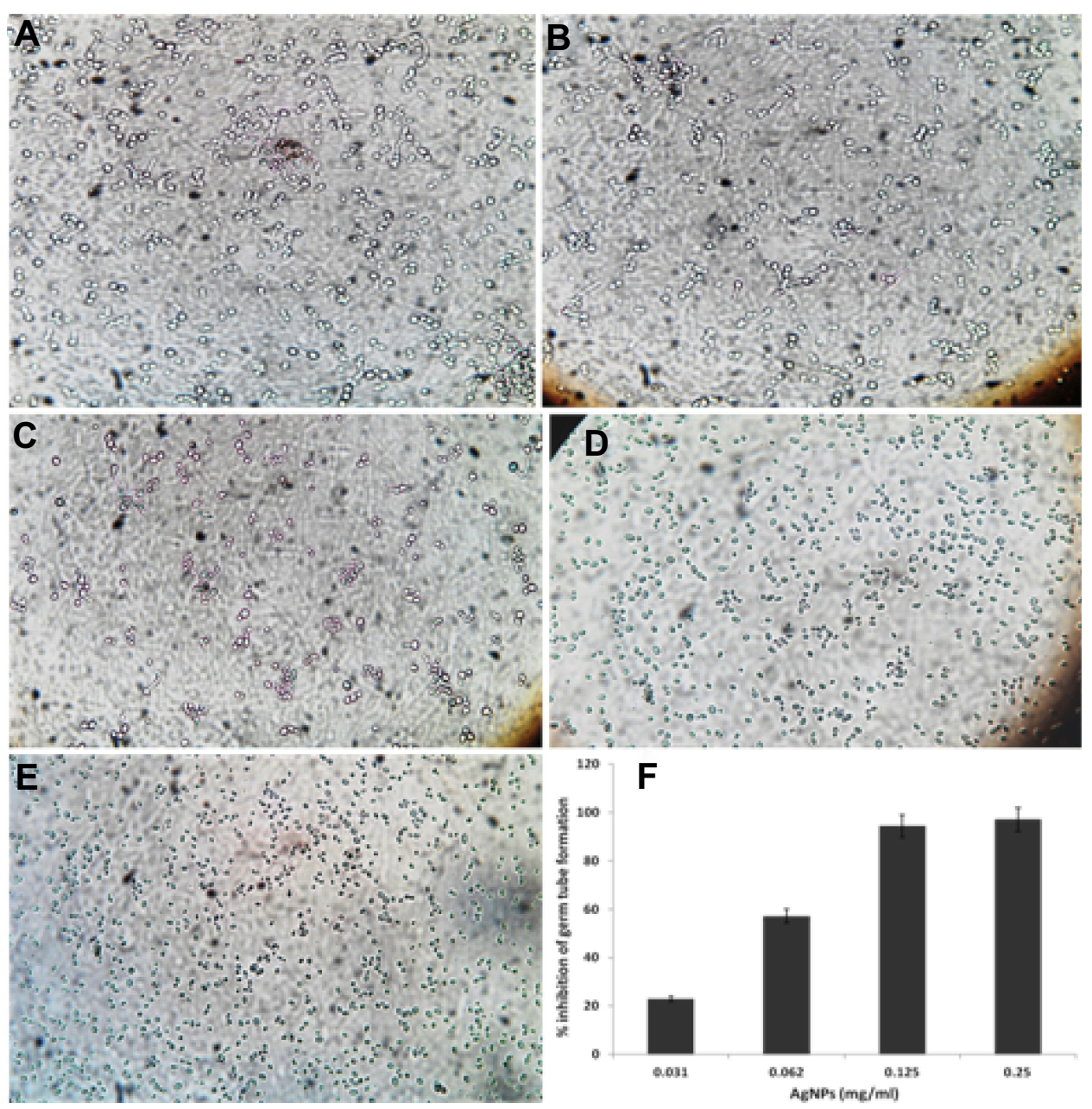

Figure 10 Effects of different concentration of ScAgNPs on germ tube formation of C. albicans. (A) control; (B) $0.03 \mathrm{I} ;$ (C) $0.062 ;$ (D) $0.125 ;$ and (E) $0.250 \mathrm{mg} / \mathrm{mL}$ of ScAgNPs. (F) Depicts the percentage inhibition of germ tube formation at various concentrations of ScAgNPs.

Abbreviation: ScAgNPs, Syzygium cumini silver nanoparticles.

$22.9 \%$ at concentrations of $0.25,0.125,0.062$, and 0.031 $\mathrm{mg} / \mathrm{mL}$, respectively (Figure $10 \mathrm{~F}$ ). Similar results were previously reported by Jalal et $\mathrm{al}^{24}$ who reported that ZnO NPs synthesized by leaf extract of Crinum Latifolium inhibit germ tube induction by $86.4 \%$ but at a high concentration, ie, $1.0 \mathrm{mg} / \mathrm{mL}^{24}$. However, in the present study ScAgNPs inhibit germ tube formation by $97.1 \%$ at 0.25 $\mathrm{mg} / \mathrm{mL}$, which is 4-times lesser than that of $\mathrm{ZnO} \mathrm{NPs}$. Recently, ${ }^{47}$ it was reported that $\mathrm{CuO} \mathrm{NPs}$ at $300 \mathrm{mg} / \mathrm{L}$ completely inhibit the germ tube formation in Candida spp. However, the exact mechanism of germ tube inhibition by nanoparticles is not clear. Halbandge et $\mathrm{al}^{48}$ reported that biosynthesized AgNPs affect Ras-mediated signal transduction pathways in C. albicans by downregulating the expression of cell elongation gene (ECE1), hyphal inducer gene (TEC), and yeast to hyphal transition genes (TUP1 and
RFG1) which are important for yeast to hyphal (Y-H) form transition. ${ }^{48}$

\section{Visualization of $C$. albicans biofilm by congo red agar and CLSM}

Another most important virulence factor that plays a major role in pathogenesis in host is biofilm formation by C. albicans. C. albicans has the ability to build biofilms more or less on all kinds of medical device, eg, cardiac valves, indwelling prosthetic devices and catheters, joint prostheses, vascular and urinary catheters, ventricular assist devices, artificial vascular bypass devices, and pacemakers. ${ }^{49}$ The extracellular polymeric substances act as a barrier to prevent the diffusion of drugs. ${ }^{50}$ Further, it has been reported that sessile cells within biofilms are more difficult to eradicate, and they have the 
ability to resist drug concentrations even 1,000-fold higher than the IC50 reported for the planktonic yeasts. ${ }^{51}$ Therefore, there is an urgent need to design and develop novel anticandidal and antibiofilm agents against these unmanageable infections. In the present study, qualitative inhibition of biofilm formation in C. albicans by ScAgNPs examined on BHIA supplemented with Congo red shows that the colonies of untreated $C$. albicans were black, which indicates the production of exopolysaccharide (EPS). However, cells treated with ScAgNPs not only inhibit the production of exopolysaccharides, but also inhibit the growth of cells (Figure S1). Muthamil et $\mathrm{al}^{52}$ reported that AgNPs strongly inhibit the EPS production in C. albicans, C. glabrata, and C. tropicalis. The visualization and quantification of biofilm and distribution of live and dead cells after treatment of ScAgNPs were evaluated by CLSM using LIVE/DEAD biofilm viability florescent stains, ie, ConA-FITC and PI. ConA (carbohydrate-binding lectin protein) conjugated with FITC is a green fluorescent stain which was used to study their binding to biofilms exopolysaccharide and live cells within the matrix. In contrast, PI is a redfluorescent nucleic acid stain which can penetrate the cells with damaged membranes. Thus, Candida cells with intact cell membranes (ie, live) are fluorescent green, whereas cells with damaged membranes (ie, dead) are fluorescent red. In the present study, CLSM analysis showed that ScAgNPs not only act on the biofilm cells, but also penetrate and damage the exopolysaccharides matrix. It was observed that ScAgNPs at a concentration of $50 \mu \mathrm{g} / \mathrm{mL}$ resulted in almost complete inhibition of biofilm formation in C. albicans (Figure 11). Recently, AgNPs synthesized by Dodonaea viscosa and Hyptis suoveolens leaf extract have inhibited biofilm formation of Candida spp. from 79 to $88 \%$ at $10 \mu \mathrm{g} / \mathrm{mL}^{52}$ Monteiro et $\mathrm{al}^{53}$ reported that colloidal suspensions of AgNPs at $54 \mu \mathrm{g} / \mathrm{mL}$ inhibit the biofilm formation approximately 54 and $90 \%$ in $C$. albicans and $C$. glabrata, respectively. The exact mechanism of inhibition of biofilm formation by AgNPs is not known. Różalska et $\mathrm{al}^{54}$ suggested that antibiofilm activity was due to the extremely easy binding and enhanced penetration of the AgNPs into the biofilm structure which disturb the lipidome of cell membranes. ${ }^{54}$ Another possible mechanism of antibiofilm activity of AgNPs could be due to inhibition of yeast morphogenesis. Inhibition of blastospores and hyphae forms by AgNPs also lead to the suppression of biofilm formation in Candida. ${ }^{54}$ Lara et $\mathrm{al}^{55}$ reported that the antibiofilm effect of AgNPs was mainly due to the disruption of the cell wall and survival of both the yeast and the filamentous forms of the Candida spp.

\section{Morphological and ultrastructural alteration caused by ScAgNPs}

Finally, the morphological and ultrastructural alteration caused by ScAgNPs on $C$. albicans was analyzed by TEM. It was observed that $C$. albicans cells treated with 50 and $100 \mu \mathrm{g} / \mathrm{mL}$ of ScAgNPs exhibited significant alterations in the cell wall and membrane (Figure 12). TEM analysis clearly shows that AgNPs not only attached and accumulate to the cell wall and membranes but also penetrates inside the cells and accumulated in the cytoplasm (Figure 12, red arrows) that may lead to the rupturing of the cell wall and disintegration of the cytoplasmic membrane (Figure 12, black arrows). The
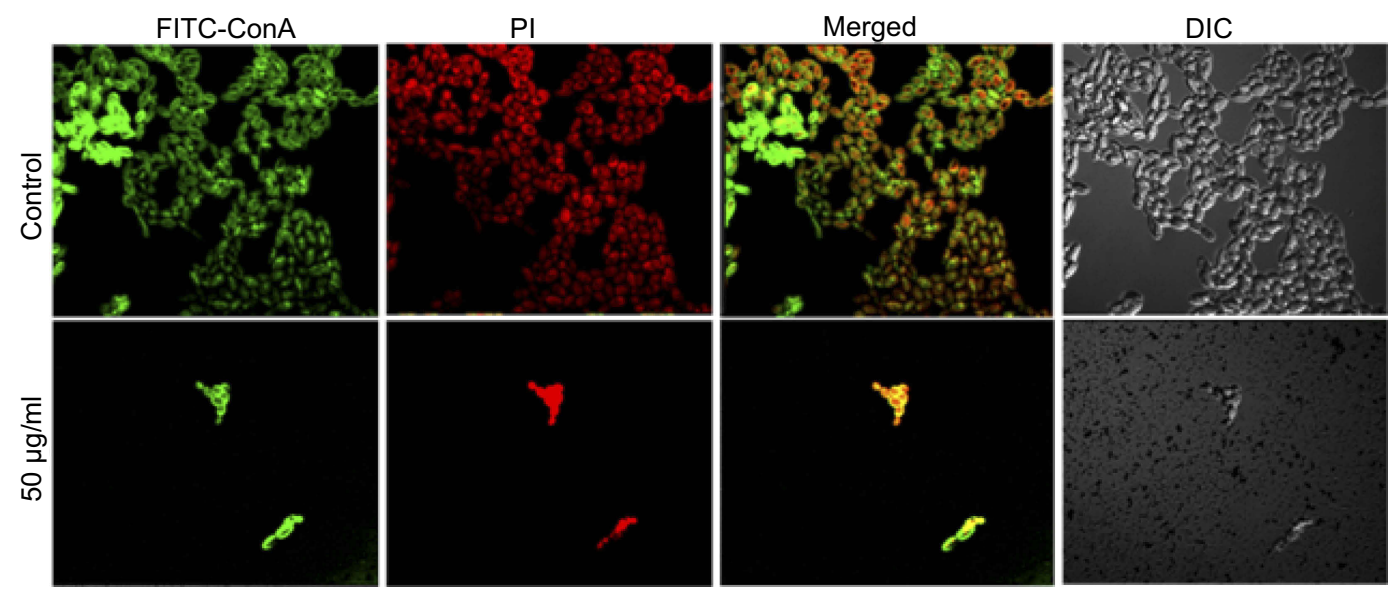

Figure II CSLM image of C. albicans biofilm. (A) Control. (B) C. albicans biofilm treated with $50 \mu g / m L o f$ ScAgNPs. Biofilms were stained with ConA-FITC and PI. ConAFITC stained $C$. albicans cells as well as exopolysaccharide matrix green. PI stained nucleic acid and fluorescent red.

Abbreviation: ScAgNPs, Syzygium cumini silver nanoparticles. 


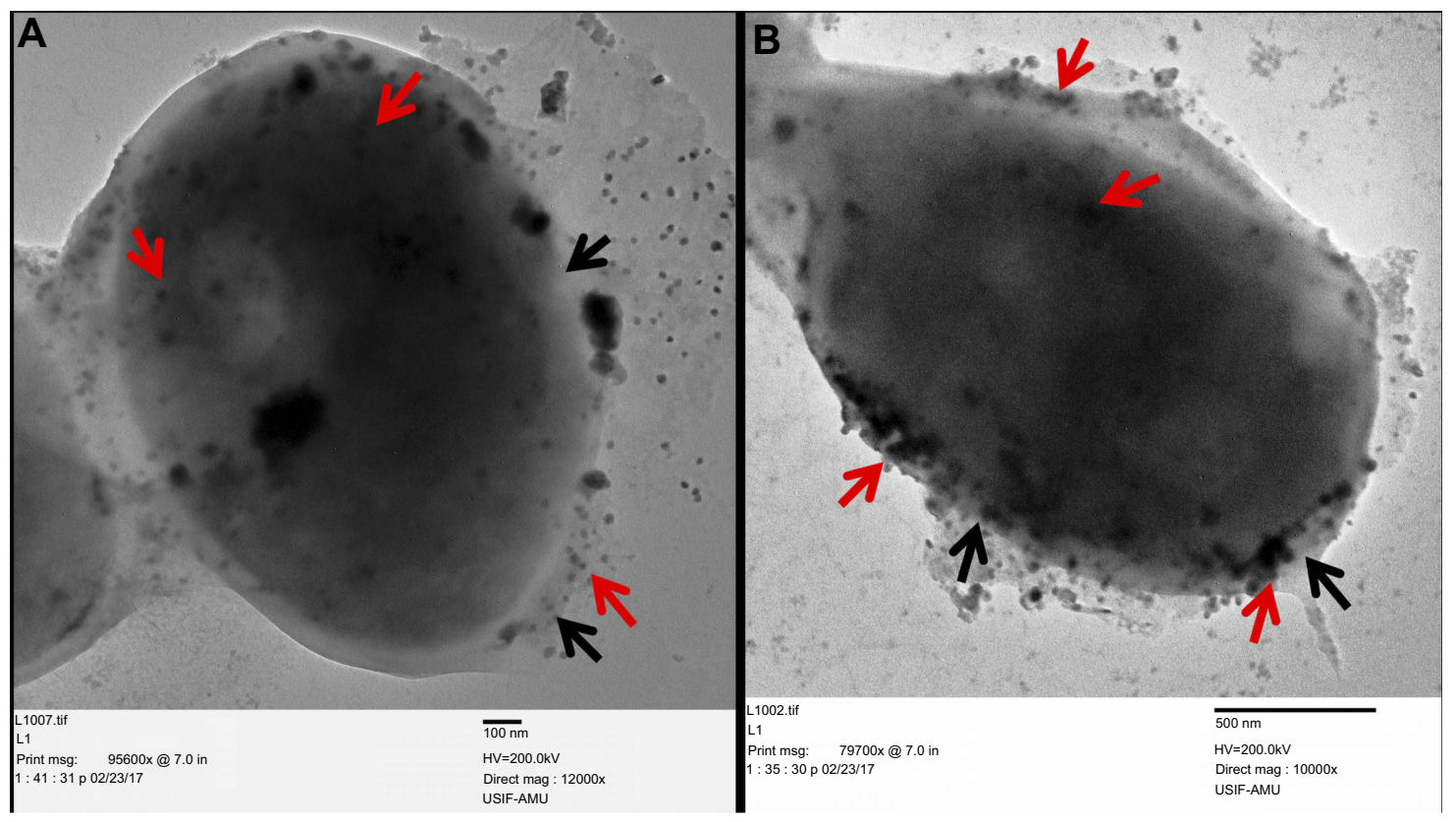

Figure 12 Ultrastructure alteration in C. albicans after treatment with 25 and $50 \mu g / \mathrm{mLof}$ ScAgNPs. The red arrows indicate attachment and internalization of AgNPs, whereas black arrows represent damage to the integrity of the cell wall and cytoplasmic membrane after treatment with AgNPs.

Abbreviation: ScAgNPs, Syzygium cumini silver nanoparticles.

present TEM result is in good agreement with the previous reports on ultrastructural analysis of the effects of AgNPs on C. albicans. ${ }^{38}$ Anticandidal mechanisms of nanomaterials are not fully understood. Kim et $\mathrm{al}^{56}$ reported that AgNPs damage the cell wall and membrane of C. albicans due to the formation of "pits and holes" on the cells surface that inhibits the budding process and finally leads to cell death. Gutierrez et al. ${ }^{35}$ reported that the fungistatic effect of AgNPs was due to the inhibition of $\beta$-glucan synthase, and the fungicidal effect was due to changes in the cell wall integrity, and loss of its mechanic resistance that leads to the cell destruction by osmotic pressure variations. However, in another study, it has been reported that AgNPs promote mitochondrial dysfunctional apoptosis, phosphatidylserine externalization, DNA, and nuclear fragmentation, and the activation of metacaspases in $C$. albicans due to programmed cell death through generation and accumulation of intercellular ROS. ${ }^{57}$ Further, Radhakrishnan et al. ${ }^{58}$ reported that generation of intracellular ROS is not the only major cause of C. albicans toxicity, and they found that AgNPs altered surface morphology, membrane fluidity, cellular microenvironment and ultrastructure, cellular ergosterol content, and fatty acid composition, especially oleic acid, which is vital for hyphal morphogenesis. ${ }^{58}$

\section{Conclusion}

In the present study, the biosynthesized ScAgNPs strongly suppressed the multiplication, germ tube and biofilm formation, and most importantly secretion of hydrolytic enzymes (viz. phospholipases, proteinases, lipases, and hemolysin) by Candia spp. The finding of the present study suggested that $\mathrm{ScAgNPs}$ could be employed as promising antifungal drugs to prevent the progress of pathogenesis in Candida spp by inhibiting the key virulence factors and development of biofilms on medical devices by applying ScAgNPs coating on medical devices and catheters. The present research work opens several avenues of further study, such as to explore the molecular mechanism of inhibition of germ tubes and biofilm formation and suppression of production of various hydrolytic enzymes by Candida spp. In vivo studies however, need to also be carried out to determine the biocompatibility, cytotoxicity, safety, and mode of action of AgNPs before being used for biomedical applications.

\section{Acknowledgments}

Mr. Mohammad Jalal is grateful to Maulana Azad National Fellowship, UGC, New Delhi, India for providing fellowship in the form of JRF. The authors are sincerely thankful to Ahmad Ali Khan and Sanjay Sharma Department of Microbiology, J.N. Medical College, 
Aligarh Muslim University, Aligarh, U.P India for their technical help and support. The authors thank the Aligarh Muslim University, Aligarh, India for providing instruments facilities and other items used in this study.

\section{Disclosure}

The authors declare that they have no conflicts of interest in this work.

\section{References}

1. Wenzel RP. Nosocomial candidemia: risk factors and attributable mortality. Clin Infect Dis. 1995;20:1531-1534. doi:10.1093/clinids/ 20.6.1531

2. Geffers C, Gastmeier P. Nosocomial infections and multidrug-resistant organisms in Germany: epidemiological data from KISS (The hospital infection surveillance system). Dtsch Arztebl Int. 2011;108:87-93.

3. Fidel PL Jr, Vazquez JA, Sobel JD. Candida glabrata: review of epidemiology, pathogenesis, and clinical disease with comparison to C. albicans. Clin Microbiol Rev. 1999;12:80-96.

4. Pereira CA, Costa AC, Silva MP, Back-Brito GN, Jorge AO. Candida albicans and virulence factors that increases its pathogenicity. In Méndez-Vilas A, editor. The Battle against Microbial Pathogens: Basic Science, Technological Advances and Educational Programs, Microbiology Series. Vol. 2. Badajoz, Spain: FORMATEX Research Center; 2015:631-636.

5. Marak MB, Dhanashree B. Antifungal susceptibility and biofilm production of Candida spp. isolated from clinical samples. Int $J$ Microbiol. 2018; Article ID 7495218. doi:10.1155/2018/7495218

6. Chandra J, Mukherjee PK, Leidich SD, et al. Antifungal resistance of candidal biofilms formed on denture acrylic in vitro. $J$ Dent Res. 2001;80:903-908. doi:10.1177/00220345010800031101

7. Ali SG, Ansari MA, Khan HM, Jalal M, Mahdi AA, Cameotra SS. Crataeva nurvala nanoparticles inhibit virulence factors and biofilm formation in clinical isolates of pseudomonas aeruginosa. $J$ Basic Microbiol. 2017;57(3):193-203. doi:10.1002/jobm.201600175

8. Ramkumar VS, Pugazhendhi A, Gopalakrishnan K, et al. Biofabrication and characterization of silver nanoparticles using aqueous extract of seaweed Enteromorpha compressa and its biomedical properties. Biotechnol Rep. 2017;14:1-7. doi:10.1016/j.btre.2017.02.001

9. Saratale GD, Saratale RG, Benelli G, et al. Anti-diabetic potential of silver nanoparticles synthesized with argyreia nervosa leaf extract high synergistic antibacterial activity with standard antibiotics against foodborne bacteria. J Clust Sci. 2017;28(3):1709-1727. doi:10.1007 s10876-017-1179-z

10. Yasir M, Singh J, Tripathi MK, Singh P, Shrivastava R. Green synthesis of silver nanoparticles using leaf extract of common arrowhead houseplant and its anticandidal activity. Pharmacogn Mag. 2018;13(Suppl 4):S840-S844. doi:10.4103/pm.pm_226_17

11. Shanmuganathan R, MubarakAli D, Prabakar D, et al. An enhancement of antimicrobial efficacy of biogenic and ceftriaxone-conjugated silver nanoparticles: green approach. Environ Sci Pollut Res. 2018;25(11):10362-10370. doi:10.1007/s11356-017-9367-9

12. Saravanan M, Arokiyaraj S, Lakshmi T, Pugazhendhi A. Synthesis of silver nanoparticles from phenerochaete chrysosporium (MTCC-787) and their antibacterial activity against human pathogenic bacteria Microb Pathog. 2018;117:68-72. doi:10.1016/j.micpath.2018.02.008

13. Pugazhendhi A, Prabakar D, Jacob JM, Karuppusamy I, Saratale RG. Synthesis and characterization of silver nanoparticles using gelidium amansii and its antimicrobial property against various pathogenic bacteria. Microb Pathog. 2018;114:41-45. doi:10.1016/j.micpath.2017.11.013
14. Oves M, Aslam M, Rauf MA, et al. Antimicrobial and anticancer activities of silver nanoparticles synthesized from the root hair extract of phoenix dactylifera. Mater Sci Eng C. 2018;89:429-443. doi:10.1016/j.msec.2018.03.035

15. Jalal M, Ansari M, Alzohairy M, et al. Biosynthesis of silver nanoparticles from oropharyngeal candida glabrata isolates and their antimicrobial activity against clinical strains of bacteria and fungi. Nanomaterials. 2018;8(8):586. doi:10.3390/nano8080586

16. Ansari MA, Alzohairy MA. One-pot facile green synthesis of silver nanoparticles using seed extract of phoenix dactylifera and their bactericidal potential against MRSA. Evid Based Complement Alternat Med. 2018; Article ID 1860280. doi:10.1155/2018/1860280

17. Soares MR, Corrêa RO, Stroppa PH, et al. Biosynthesis of silver nanoparticles using caesalpinia ferrea (Tul.) martius extract: physicochemical characterization, antifungal activity and cytotoxicity. PeerJ. 2018;19(6):e4361. doi:10.7717/peerj.4361

18. Saratale RG, Karuppusamy I, Saratale GD, et al. A comprehensive review on green nanomaterials using biological systems: recent perception and their future applications. Colloids Surf B Biointerfaces. 2018;170:20-35. doi:10.1016/j.colsurfb.2018.05.045

19. Saravanan M, Barik SK, MubarakAli D, Prakash P, Pugazhendhi A. Synthesis of silver nanoparticles from bacillus brevis (NCIM 2533) and their antibacterial activity against pathogenic bacteria. Microb Pathog. 2018;116:221-226. doi:10.1016/j. micpath.2018.01.038

20. Muthulakshmi K, Uma C. Antimicrobial activity of bacillus subtilis silver nanoparticles. Front Biosci (Elite Edition). 2019;11:89-101.

21. Rautela A, Rani J, Das MD. Green synthesis of silver nanoparticles from tectona grandis seeds extract: characterization and mechanism of antimicrobial action on different microorganisms. J Anal Sci Technol. 2019;10(1):5. doi:10.1186/s40543-018-0163-z

22. Hajjar FHE, Jebali A, Hekmatimoghaddam S. The inhibition of Candida albicans secreted aspartyl proteinase by triangular gold nanoparticles. Nanomed J. 2015;2:54-59.

23. Hamid S, Zainab S, Faryal R, Ali N, Sharafat I. Inhibition of secreted aspartyl proteinase activity in biofilms of Candida species by mycogenic silver nanoparticles. Artif Cells Nanomed Biotechnol. 2018;46 (3):551-557. doi:10.1080/21691401.2017.1328688

24. Jalal M, Ansari MA, Ali SG, Khan HM, Rehman S. Anticandidal activity of bioinspired ZnO NPs: effect on growth, cell morphology and key virulence attributes of Candida species. Artif Cells Nanomed Biotechnol. 2018;46(sup1):912-925. doi:10.1080/21691401.2018.1439837

25. Ali SG, Ansari MA, Khan HM, Jalal M, Mahdi AA, Cameotra SS. Antibacterial and antibiofilm potential of green synthesized silver nanoparticles against imipenem resistant clinical isolates of P. aeruginosa. Bionanoscience. 2018;8(2):544-553. doi:10.1007/s12668-018-0505-8

26. Jalal M, Ansari MA, Shukla AK, et al. Green synthesis and antifungal activity of A12O3 NPs against fluconazole-resistant Candida spp isolated from a tertiary care hospital. RSC $A d v$. 2016;6(109):107577107590. doi:10.1039/C6RA23365A

27. Ravichandran S, Muthuraman S. Examining the anti-candidal activity of 10 selected Indian herbs and investigating the effect of lawsonia inermis extract on germ tube formation, protease, phospholipase, and aspartate dehydrogenase enzyme activity in Candida albicans. Indian $J$ Pharmacol. 2016;48(1):47-52. doi: 10.4103/0253-7613.174523

28. Xu Y, Wang D, Mu XQ, Zhao GA, Zhang KC. Biosynthesis of ethyl esters of short-chain fatty acids using whole-cell lipase from Rhizopus chinesis CCTCC M201021 in non-aqueous phase. J Mol Catal B Enzym. 2002;18 (1-3):29-37. doi:10.1016/S1381-1177(02)00056-5

29. Subha TS, Gnanamani A, Mandal AB. Role of TMPMP and TMAP on virulence factors of C. albicans. Glob J Biochem. 2011;2(1):74-80.

30. Lee JH, Kim YG, Cho MH, Kim JA. 7-fluoroindole as an antivirulence compound against pseudomonas aeruginosa. FEMS Microbiol Lett. 2012;329:36-44. doi:10.1111/j.1574-6968.2012.02500.x 
31. Ansari MA, Khan HM, Khan AA, Cameotra SS, Pal R. Antibiofilm efficacy of silver nanoparticles against biofilm of extended spectrum $\beta$-lactamase isolates of escherichia coli and klebsiella pneumoniae. Appl Nanosci. 2014;4(7):859-868. doi:10.1007/s13204-013-0266-1

32. Banerjee J, Narendhirakannan RT. Biosynthesis of silver nanoparticles from syzygium cumini (L.) seed extract and evaluation of their in vitro antioxidant activities. Dig J Nanomater Biostruct. 2011;6(3):961-968.

33. Kanthammal S, Jebanesan A, Kovendan K, Subramaniam J, Vijay M. Novel insecticides of syzygium cumini fabricated silver nanoparticles against filariasis, malaria, and dengue vector mosquitoes. Int $J$ Mosq Res. 2018;5(5):95-106.

34. Atale N, Saxena S, Nirmala JG, Narendhirakannan RT, Mohanty S, Rani V. Synthesis and characterization of sygyzium cumini nanoparticles for its protective potential in high glucose-induced cardiac stress: a green approach. Int J Appl Biotechnol Biochem. 2017;181 (3):1140-1154. doi:10.1007/s12010-016-2274-6

35. Gutiérrez JA, Caballero S, Díaz LA, Guerrero MA, Ruiz J, Ortiz CC. High antifungal activity against candida species of monometallic and bimetallic nanoparticles synthesized in nanoreactors. ACS Biomater Sci Eng. 2018;4(2):647-653. doi:10.1021/acsbiomaterials.7b00511

36. Staniszewska M, Bondaryk M, Piłat J, Siennicka K, Magda U, Kurzatkowski W. Virulence factors of Candida albicans. Przegl Epidemiol. 2012;66(4):629-633.

37. Panáček A, Kolář M, Večeřová R, et al. Antifungal activity of silver nanoparticles against Candida spp. Biomaterials. 2009;30(31):63336340. doi:10.1016/j.biomaterials.2009.07.065

38. Vazquez-Muñoz R, Avalos-Borja M, Castro-Longoria E. Ultrastructural analysis of Candida albicans when exposed to silver nanoparticles. PLoS One. 2014;9(10):e108876. doi:10.1371/journal. pone. 0108876

39. Mallmann EJ, Cunha FA, Castro BN, Maciel AM, Menezes EA, Fechine PB. Antifungal activity of silver nanoparticles obtained by green synthesis. Rev Inst Med Trop Sao Paulo. 2015;57(2):165-167. doi:10.1590/S0036-46652015000200011

40. Pandey N, Gupta MK, Tilak R. Extracellular hydrolytic enzyme activities of the different Candida spp. isolated from the blood of the intensive care unit-admitted patients. $J$ Lab Physicians. 2018;10 (4):392.

41. Stehr F, Kretschmar M, Kröger C, Hube B, Schäfer W. Microbial lipases as virulence factors. J Mol Catal B Enzym. 2003;22(56):347-355. doi:10.1016/S1381-1177(03)00049-3

42. Luo G, Samaranayake LP, Cheung BP, Tang G. Reverse transcriptase polymerase chain reaction (RT-PCR) detection of HLP gene expression in Candida glabrata and its possible role in vitro haemolysin production. Apmis. 2004;112:283-290. doi:10.1111/j.1600-0463.2004.apm112040509.x

43. Tsang CS, Chu FC, Leung WK, Jin LJ, Samaranayake LP, Siu SC. Phospholipase, proteinase and haemolytic activities of Candida albicans isolated from oral cavities of patients with type 2 diabetes mellitus. J Med Microbiol. 2007;56:1393-1398. doi:10.1099/ jmm.0.47303-0

44. Peters BM, Palmer GE, Nash AK, Lilly EA, Fidel PL, Noverr MC. Fungal morphogenetic pathways are required for the hallmark inflammatory response during Candida albicans vaginitis. Infect Immun. 2014;82(2):532-543. doi:10.1128/IAI.01417-13
45. Modrzewska B, Kurnatowski P. Adherence of Candida sp. to host tissues and cells as one of its pathogenicity features. Ann Parasitol. 2015;61:1.

46. Carradori S, Chimenti P, Fazzari M, Granese A, Angiolella L. Antimicrobial activity, synergism and inhibition of germ tube formation by crocus sativus-derived compounds against Candida spp. $J$ Enzyme Inhib Med Chem. 2016;31(sup2):189-193. doi:10.1080/ 14756366.2016.1180596

47. Mudiar R, Kelkar-Mane V. Targeting fungal menace through copper nanoparticles and tamrajal .J Ayurveda Integr Med. 2018. S09759476(17)30481-3. doi:10.1016/j.jaim.2018.02.134

48. Halbandge SD, Jadhav AK, Jangid PM, Shelar AV, Patil RH, Karuppayil SM. Molecular targets of biofabricated silver nanoparticles in Candida albicans. J Antibiot. 2019. doi:10.1038/s41429-0190185-9

49. Deorukhkar SC, Saini S. Medical device-associated Candida infections in a rural tertiary care teaching hospital of India. Interdiscip Perspect Infect Dis. 2016; Article ID 1854673. doi:10.1155/2016/ 1854673

50. Seneviratne CJ, Jin L, Samaranayake LP. Biofilm lifestyle of Candida: a mini review. Oral Dis. 2008;14:582-590. doi:10.1111/ j.1601-0825.2008.01490.x

51. Taff HT, Mitchell KF, Edward JA, Andes DR. Mechanisms of Candida biofilm drug resistance. Future Microbiol. 2013;8:13251337. doi:10.2217/fmb.13.101

52. Muthamil S, Devi VA, Balasubramaniam B, Balamurugan K, Pandian SK. Green synthesized silver nanoparticles demonstrating enhanced in vitro and in vivo antibiofilm activity against Candida spp. J Basic Microbiol. 2018;58(4):343-357. doi:10.1002/jobm.2 01700529

53. Monteiro DR, Silva S, Negri M, et al. Silver colloidal nanoparticles: effect on matrix composition and structure of $\mathrm{C}$ andida albicans and C andida glabrata biofilms. J Appl Microbiol. 2013;114(4):11751183. doi:10.1111/jam.12102

54. Różalska B, Sadowska B, Budzyńska A, Bernat P, Różalska S, Mukherjee A. Biogenic nanosilver synthesized in metarhizium robertsii waste mycelium extract-as a modulator of Candida albicans morphogenesis, membrane lipidome and biofilm. PLoS One. 2018;13 (3):e0194254. doi:10.1371/journal.pone.0194254

55. Lara HH, Romero-Urbina DG, Pierce C, Lopez-Ribot JL, ArellanoJiménez MJ, Jose-Yacaman M. Effect of silver nanoparticles on Candida albicans biofilms: an ultrastructural study. $J$ Nanobiotechnology. 2015;13(1):91. doi:10.1186/s12951-015-0147-8

56. Kim KJ, Sung WS, Suh BK, et al. Antifungal activity and mode of action of silver nanoparticles on Candida albicans. Biometals. 2009;22:235-242. doi:10.1007/s10534-008-9159-2

57. Hwang IS, Lee J, Hwang JH, Kim KJ, Lee DG. Silver nanoparticles induce apoptotic cell death in Candida albicans through the increase of hydroxyl radicals. Febs J. 2012;279:1327-1338. doi:10.1111/ j.1742-4658.2012.08527.x

58. Radhakrishnan VS, Mudiam MK, Kumar M, Dwivedi SP, Singh SP, Prasad T. Silver nanoparticles induced alterations in multiple cellular targets, which are critical for drug susceptibilities and pathogenicity in fungal pathogen (Candida albicans). Int $J$ Nanomedicine. 2018;13:2647. doi:10.2147/IJN.S177627 


\section{Supplementary material}
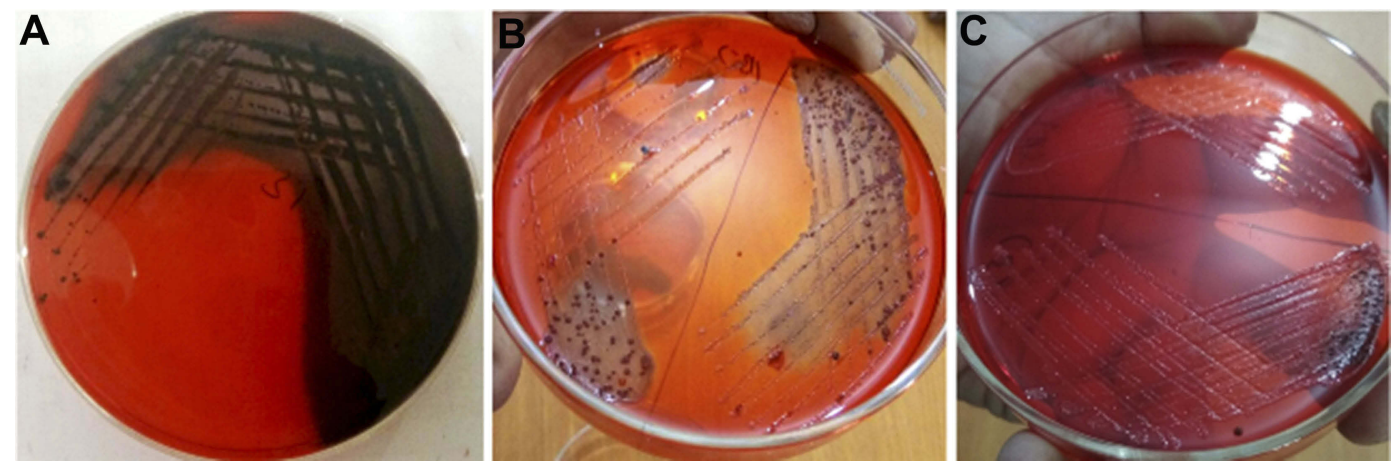

Figure SI Ability of biofilm formation of C. albicans on BHI agar supplemented with Congo red and ScAgNPs. (A) Control (without ScAgNPs) showing black crystalline colonies indicate the exopolysaccharides production. Plates (B) and (C) treated with 0.025 and $0.05 \mathrm{mg} / \mathrm{mL}$ of ScAgNPs showing inhibition of exopolysaccharide synthesis. Abbreviation: ScAgNPs, Syzygium cumini silver nanoparticles.

\section{Publish your work in this journal}

The International Journal of Nanomedicine is an international, peerreviewed journal focusing on the application of nanotechnology in diagnostics, therapeutics, and drug delivery systems throughout the biomedical field. This journal is indexed on PubMed Central, MedLine, CAS, SciSearch ${ }^{\mathbb{R}}$, Current Contents ${ }^{\mathbb{B}} /$ Clinical Medicine,
Journal Citation Reports/Science Edition, EMBase, Scopus and the Elsevier Bibliographic databases. The manuscript management system is completely online and includes a very quick and fair peer-review system, which is all easy to use. Visit http://www.dovepress.com/ testimonials.php to read real quotes from published authors. 